\title{
A Practical Journal Usage Technique
}

\begin{abstract}
A practical journal usage technique is currently being employed at the Case Western Reserve University Libraries. This technique can be used in a wide variety of libraries, with extensive collections, for an indefinite period of time and with minimal expense. The associated study yields relevant management information from a straightforward analysis. The fundamental result of the study is a stable segregation of the collection into two components, those volumes and titles that are used and those that are not used. A technique for rating the relative liability of the unused titles is also provided.
\end{abstract}

\section{I} N RECENT YEARS the increasing cost of journal subscriptions and the rapid growth of the journal literature have had a significant impact on the stable or declining budgets and fixed space of many academic libraries. ${ }^{1}$ These circumstances have created the need for more cost-conscious management of the journal literature collection in major academic libraries. Improved management of the collection can be facilitated by knowledge of how the use of the collection is distributed over the individual titles.

Unfortunately, it is difficult and expensive to monitor the use of large collections on an ongoing basis, particularly when no record of use is generated by standard procedures, such as circulation records. The technique described below provides a simple, inexpensive way to obtain the necessary management information for an indefinite period of time.

W. M. Shaw, Jr., is assistant professor, School of Library Science, Case Western Reserve University (CWRU), Cleveland, Ohio. This article is a revised and updated version of a paper originally presented to the Library Research Round Table at the Annual Conference of the American Library Association in June 1977. The data for this study were collected by several CWRU library school interns: Katherine Wilson, Karen Croneis, Jane Hodges, and James Arifayan. Their efforts are gratefully acknowledged. This study was conducted by the CWRU Libraries office of research and systems, coordinated by Esther Greenberg.

\section{BACKGROUND}

There have been numerous journal usage studies reported in the literature. These studies have addressed such issues as:

1. which titles should be added to the collection;

2. which titles might be canceled, discarded, or stored;

3. which titles might be bound in a less expensive manner, or not at all; and

4 . which titles might be converted to microform.

The data required to support decisions in the above areas have been taken from a variety of sources including: citation analyses, ${ }^{2-5}$ interlibrary loan requests, ${ }^{6}$ photocopy requests, ${ }^{7,8}$ questionnaires, ${ }^{9}$ loan slips, ${ }^{10}$ shelving statistics, ${ }^{11-13}$ and other internal measures.

While the origin of the data varies, there are several characteristics that are frequently observed in these studies.

1. The data are collected during a limited time period, e.g., four months or one semester.

2. The studies frequently occur in special libraries or otherwise limited collections, especially scientific and medical collections.

3 . The results of the studies are customarily expressed as a ranking of titles based on the relative, absolute (not normalized) frequency of use. ${ }^{14}$ The same measure is generally employed to show how the use varies as a function of volume age. 
Studies in which the data are derived and analyzed in the general manner described above are defined here as utilizing the traditional journal usage technique.

\section{DISCUSSION OF THE}

\section{Traditional Journal Usage Technique}

The three characteristics that the traditional studies frequently share possess inherent disadvantages.

First, it is difficult to determine how long such a study should be conducted before reliable results can be obtained. While a recent study has shown that the majority of low-use titles can be identified in a relatively short period of time, ${ }^{15}$ such results do not diminish the need for long-term studies.

There are two reasons for this:

1. It cannot be assumed that the same limited time period will identify the same percentage of those titles with a given use characteristic in all libraries. Consequently, each library will have to determine this time period independently until or unless it can be shown repeatedly that the same time period has the same meaning in a large number of libraries.

2. Neither the library nor the environment in which it operates is static. Management decisions can affect the usage pattern in such a way that other studies might be required. Clearly, new titles are added to collections (even these days), and it would be desirable to begin assessing their use immediately. Moreover, changes in the curriculum or the clientele can influence the demands placed on an academic library.

In addition to these uncertainties, it is not clear how far into the future the results of a study conducted over a limited time period can be meaningfully used as a management tool.

Second, the results derived from small, specialized collections do not lend themselves to generalizations that may be adopted by large academic and research libraries. The attention to scientific and medical collections provides little data applicable to diverse collections which include holdings in the humanities and social sciences.

The issue here is actually more fundamental. Library managers must make decisions that require title-by-title distinctions. It is unlikely that decisions of this type, however scientifically motivated, could be universally adopted, even by similar libraries. The fact that a title is not used in library A is no guarantee that it is of no use to library B. Since generalizable results are not likely to be produced, a generalizable technique is a more reasonable objective.

Finally, the data generation, collection, and analysis phases of the traditional frequency-of-use study are typically cumbersome, labor-intensive, and expensive exercises. The associated ranking analysis seeks to distinguish between the relative number of uses experienced by the individual titles but provides no simple measure for the performance of the collection. The most common summary statistic reported in the literature gives the percentage of the collection that generates some percentage of the uses, the $20 / 80$ syndrome.

This is an interesting statistic, but it does not allow a library to monitor its journal performance as a function of time; nor does it allow two libraries to compare their relative performance. Moreover, it is hardly useful for the library manager to know that title A has been used 150 times and title B has been used 15 times, during some limited time period, when a substantial proportion of the collection generates no use during an extended time period. The traditional journal study may generate substantial quantities of data that are of doubtful practical utility. ${ }^{16}$

It is clear that it would be desirable to have a technique which could be used in large collections, for an indefinite period of time, with minimal expense, and which would yield relevant management information from a straightforward analysis. A practical journal usage technique is currently being employed at the Case Western Reserve University (CWRU) Libraries that possesses these useful characteristics.

\section{DESCRIPTION OF THE CWRU STUDY}

The CWRU study is restricted to the bound journal volumes which the users are encouraged not to reshelve. The use data are generated by simply applying a small, pressure-sensitive label to the spine of a volume the first time it is reshelved by lilibrary personnel. A tagged volume is re- 
shelved with no further action. Thus at any given time the tagged volumes represent those that have been used at least once since the study began.

Current issues may be included if the tag is affixed adjacent to the title label on the shelf, i.e., by tagging the shelf not the journal issue. These tags indicate whether or not the current issues of journal titles are used. The data are collected periodically by counting the total number (or an appropriate sample) of volumes and titles and those that have been tagged.

The associated analysis simply requires computing the cumulative fraction of volumes and titles that have been used during progressively expanding time periods. A similar technique has been used as a weeding criterion for monographs in a public library. ${ }^{17}$

The cumulative fraction of bound volumes and/or titles used in expanding time periods can serve as a simple measure of performance for the journal collection. This measure would be expected to increase rapidly at first, then more slowly, approaching a constant fraction as time progresses. When the constant fraction condition is reached, there is a high probability that those volumes or titles that have not been used will not experience significant use in the foreseeable future.

The fundamental result of this study is, then, a stable segregation of the journal literature collection into two categories: (1) those volumes and titles that are used and (2) those that are not used. Thus decisions regarding the disposition of volumes or titles can be made with confidence that they will stand the test of time. Moreover, when the constant fraction condition is reached, the shelvers would be applying labels infrequently. Consequently, the procedural costs, in terms of the time required to update the data, diminish as time progresses.

\section{RESUlTS OF THE CWRU STUDY}

The CWRU Libraries are composed of two major libraries (Freiberger and Sears) and their satellites. The Freiberger Library contains materials in the humanities, social sciences, and behavioral sciences. The Sears Library contains materials in the sciences, engineering, management, and economics.
The results reported here were derived from the public access areas (not storage), which for Freiberger include approximately 2,700 titles and 59,000 volumes and which for Sears include approximately 1,600 titles and 24,000 volumes.

The current study of the journal literature collection of the two libraries was begun in October 1975. Data have been collected and analyzed periodically since that time. Figure 1 gives the cumulative fraction of volumes and titles used as a function of time for the two libraries. The results associated with the Sears collection are different from those associated with the Freiberger collection in terms of overall use and in terms of the tendency toward the constant fraction condition.

The lower overall utilization of the Freiberger collection has been influenced by the fact that a substantial portion of the journal titles were classified and shelved among the monographs. The classified titles showed relatively little use compared to the majority of the collection, which is arranged alphabetically by title. The existence and location of these classified titles were probably not apparent to all users. Many of these titles were declassified and integrated into the main collection during the course of this study. Currently, the use of these titles is comparable to that of the rest of the collection. This event demonstrates how a management decision can affect the use of the collection.

The tendency toward the constant fraction condition has been distorted by an unusual event at the Sears Library. The Sears curve for titles shows an anomalous increase between the eighth and the twelfth month. This increase is due indirectly to a flood of the first floor of that library in August 1975. The first floor contained many older volumes of important titles. In the aftermath of this event, it was determined that no journal titles would be housed in this area and that a selected group would be shelved in the main collection on the second floor.

In order to provide space for the selected items and other additions to the collection some volumes and titles had to be moved to storage. Those items moved to storage showed little or no use in a previous traditional study and the current study. Dur- 


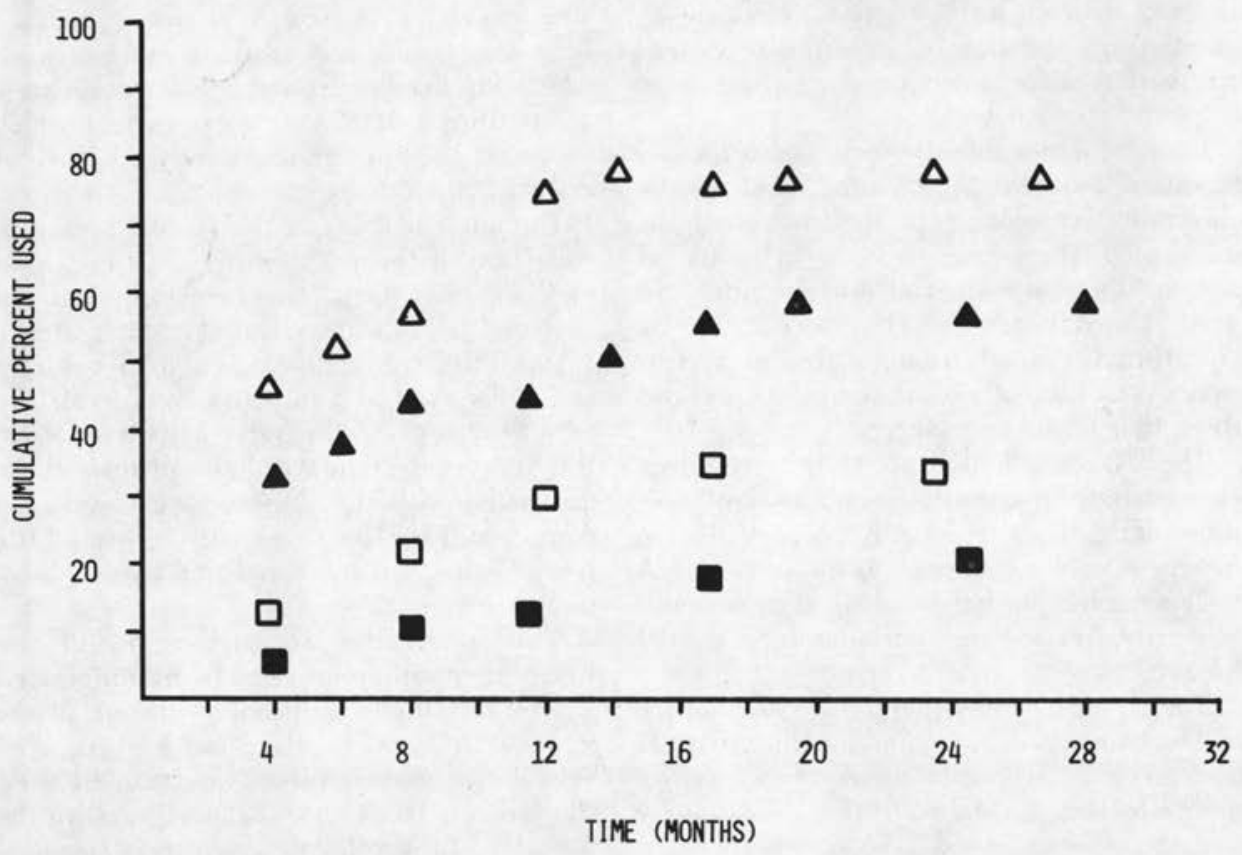

$\triangle$ Sears Library-Titles

$\square$ Sears Library-Volumes

$\Delta$ Freiberger Library-Titles

- Freiberger Library-Volumes

Fig. 1

Cumulative Percent of Volumes and Titles Used as a Function of Time-Freiberger and Sears Libraries

ing the above interval many of the unused volumes and titles had been removed, but no "new" items had taken their place. Consequently, the denominator of the fraction for both volumes and titles had been reduced while the numerator remained essentially the same.

As a result, the fraction of titles used was noticeably increased. This event provides a graphic illustration of how the environment can affect a journal usage study. One can certainly identify other external events with a greater likelihood of occurrence.

The Freiberger title curve shows a leveling tendency over the same interval that the Sears title curve shows the sudden increase. This is the more expected result since the period between the eighth and the twelfth month includes the summer session (June, July, and August), during which the use diminishes significantly.

The most striking feature of the analysis to date is the small fraction of volumes and titles that have been used in the two libraries. At the Sears Library about 35 percent of the volumes and about 77 percent of the titles generate use. At the Freiberger Library about 22 percent of the volumes and about 58 percent of the titles generate use.

These results indicate that over 61,000 volumes and 1,500 titles have generated no use during the course of this study. The stability of the curves suggests that few of these volumes and titles will begin to generate use in the foreseeable future. Consequently, these unused items represent a substantial resource from the viewpoint of identifying candidates for cancellation, storage, conversion to microform, or redistribution within a consortium.

\section{ASSESSING THE ReLATIVE LiabiLITY OF UNUSED TITLES}

While zero use must be considered a sig- 
nificant factor, it cannot serve as the exclusive justification for subscription cancellation or other access-limiting decisions. Zero use may be considered the necessary but not sufficient cause for subscription cancellation. Internal approval of the associated faculty, collection development staff, and reference staff should also be sought in order to ensure that the intellectual integrity of the collection is preserved.

The number of unused titles that must be subjected to these additional criteria may be substantial, as seen above. Consequently, it is appropriate to have a systematic method to deal with them. This can be accomplished by ranking these titles according to the total cost of maintaining each of them.

The total yearly maintenance cost for each unused title may be computed by summing the yearly subscription cost (S), the yearly binding cost (B), and the yearly storage cost (C). While the first of these costs may be determined directly, the latter two require some indirect computation. In order to determine the yearly binding cost, the number of times each title is bound per year and the average cost of binding a journal volume are required.

The average binding cost should include the average fee paid to the binder plus an average value for the sum of all internal costs attendant to the journal binding effort of the library. For each title the product of the number of times it is bound per year times the average binding cost per volume yields the yearly binding cost (B) for that title.

In order to determine the yearly storage cost three factors are required: (1) the yearly maintenance cost per square foot of the library, (2) the area occupied by the average range containing journal volumes, and (3) the average number of shelving feet per range. The yearly cost per linear foot of space devoted to journal volumes is then (1) times (2) divided by (3). Thus for each title the product of the number of linear feet it occupies times the yearly cost per linear foot devoted to journal volumes yields the storage cost (S) for that title.

The total yearly cost (T) of maintaining each unused title may be computed by $\mathrm{T}=$ $\mathrm{S}+\mathrm{B}+\mathrm{C}$. The unused titles may be ranked according to $(T)$, where the title with the greatest $(\mathrm{T})$ possesses the greatest liability (in terms of expense) to the library. The appropriate procedure, then, is to identify the first title on the ranked list and to work systematically toward the last title.

Libraries can expect to achieve a substantial savings in dollars and space by addressing the unused portion of the collection. Moreover, the associated decisions can be made with confidence that they will generate minimal frustration among the library's clientele.

\section{CONCLUSION}

The CWRU study provides current use data on a title-by-title basis that may be retrieved by visual inspection of the ranges containing bound journal volumes and issues. Items that are not used during long periods of time, due to age or lack of subject relevance, may be easily identified. The unused titles may be investigated systematically in order to achieve the greatest return for the least expenditure of time and effort.

Since the technique reported here can be adopted by a wide variety of libraries, it can contribute to the cost-effective management of the journal resources of a consortium, by ensuring that the individual libraries do not cancel titles that are used locally. This is important since lower subscription costs in an individual library could be achieved at the expense of escalating interlibrary loan expenditures for the other associated libraries.

The CWRU Libraries are members of a consortium of North East Ohio Major Academic Libraries (NEOMAL) that is making use of this technique to aid in the cooperative management of its journal resources. ${ }^{18}$

\section{REFERENCES}

1. R. De Gennaro, "Escalating Journal Prices: Time to Fight Back," American Libraries 8:69-74 (Feb. 1977).

2. M. B. M. Campbell, "A Survey of the Use of Science Periodicals in Wolverhampton Polytechnic Library," Research in Librarianship 5:39-72 (May 1974).

3. P. Scales, "Citation Analyses as Indicators of the Use of Serials: A Comparison of Ranked Title Lists Produced by Citation Counting and from Use Data," Journal of Documenta- 
tion 32:17-25 (March 1976).

4. C. A. Seymour, "Weeding the Collection: A Review of Research on Identifying Obsolete Stock Part II Serials," Libri 22:183-89 (1972).

5. A. S. Tobias, "The Yule Curve Describing Periodical Citations by Freshmen: Essential Tool or Abstract Frill?" Journal of Academic Librarianship 1:14-16 (1975).

6. M. B. M. Campbell, "A Survey of the Use of Science Periodicals."

7. V. A. Basile and R. W. Smith, "Evolving the 90\% Pharmaceutical Library," Special Libraries 61:81-86 (Feb. 1970).

8. R. W. Wender, "Hospital Journal Title Usage Study," Special Libraries 66:532-37 (Nov. 1975).

9. S. L. Peterson, "Patterns of Use of Periodical Literature," College \& Research Libraries 30:422-30 (Sept. 1969).

10. T. P. Fleming and F. G. Kilgour, "Moderately and Heavily Used Biomedical Journals," Bulletin of the Medical Library Association 52:234-41 (Jan. 1964).

11. C-c. Chen, "The Use Patterns of Physics Journals in a Large Academic Research Library," Journal of the American Society for Information Science 24:254-65 (July/Aug. 1972).
12. D. C. Langlois and J. V. Von Schulz, "Journal Usage Survey Method and Application," Special Libraries 64:239-44 (May/June 1973).

13. P. Tibbetts, "A Method for Estimating the In-House Use of the Periodical Collection in the University of Minnesota Bio-Medical Library," Bulletin of the Medical Library Association 62:37-48 (Jan. 1974).

14. S. C. Bradford, Documentation (London: Crosby Lockwood, 1948).

15. C. B. Wenger and J. Childress, "Journal Evaluation in a Large Research Library," Journal of the American Society for Information Science 28:293-99 (Sept. 1977).

16. M. B. Line and A. Sandison, "Practical Interpretation of Citation and Library Use Studies," College \& Research Libraries 36:393-96 (Sept. 1975).

i17. S. J. Slote, Weeding Library Collections (Littleton, Colo.: Libraries Unlimited, 1975).

18. K. Brewer, G. Pitkin, and N. Edgar, "A Method for Cooperative Serials Selection and Cancellation through Consortium Activities," Journal of Academic Librarianship 4:204-8 (Sept. 1978). 